\title{
Author Correction: Federal energy R\&D: Startups supported by ARPA-E were more innovative than others but an investment gap may remain
}

Anna Goldstein (D), Claudia Doblinger (D), Erin Baker (1) and Laura Díaz Anadón

Correction to: Nature Energy https://doi.org/10.1038/s41560-020-00691-8, published online 14 September 2020.

In the version of this Policy Brief originally published, in the Acknowledgements, the support from the Belfer Center's Science, Technology, and Public Policy Program was mistakenly not mentioned; this information has now been added. All versions of the Policy Brief have been amended.

Published online: 25 September 2020

https://doi.org/10.1038/s41560-020-00712-6

(c) The Author(s), under exclusive licence to Springer Nature Limited 2020 